\title{
Silicone Oil Microdroplets Can Induce Antibody Responses Against Recombinant Murine Growth Hormone In Mice
}

\author{
Carly Fleagle Chisholm, ${ }^{1}$ Abby E. Baker, ${ }^{1}$ Kaitlin R. Soucie, ${ }^{1}$ Raul M. Torres, ${ }^{2}$ John F. \\ Carpenter, ${ }^{3}$ Theodore W. Randolph ${ }^{1 *}$
}

${ }^{1}$ Department of Chemical and Biological Engineering, University of Colorado, Boulder, Colorado 80309

${ }^{2}$ Department of Immunology \& Microbiology, University of Colorado School of Medicine, Aurora, Colorado 80045

${ }^{3}$ Department of Pharmaceutical Sciences, University of Colorado Anschutz Medical Campus, Aurora, Colorado 80045

*Corresponding author, Theodore W. Randolph, address: 3415 Colorado Ave, Boulder, CO 80303. Email: Theodore.randolph@ colorado.edu, phone: 303-492-4776, fax: 303-492-8425. 


\section{ABSTRACT}

Therapeutic protein products can cause adverse immune responses in patients. The presence of sub-visible particles is a potential contributing factor to the immunogenicity of parenterallyadministered therapeutic protein formulations. Silicone oil microdroplets, which derive from silicone oil used as a lubricating coating on barrels of prefilled glass syringes, are often found in formulations. In this study, we investigated the potential of silicone oil microdroplets to act as adjuvants to induce an immune response in mice against a recombinant murine protein. Antibody responses in mice to subcutaneous injections of formulations of recombinant murine growth hormone $(\mathrm{rmGH})$ that contained silicone oil microdroplets were measured and compared to responses to oil-free rmGH formulations. When $\mathrm{rmGH}$ formulations containing silicone oil microdroplets were administered once every other week, anti-rmGH antibodies were not detected. In contrast, mice exhibited a small IgG1 response against rmGH when silicone oilcontaining rmGH formulations were administered daily, and an anti-rmGH IgM response was observed at later time points. Our findings showed that silicone oil microdroplets can act as an adjuvant to promote a break in immunological tolerance and induce antibody responses against a recombinant self-protein.

KEYWORDS: protein formulation, protein structure, immune response, immunogenicity, protein aggregation, subvisible particles, particle size, prefilled syringes, silicone oil, adjuvant effect 


\section{INTRODUCTION}

The presence of sub-visible particles in injectable formulations of therapeutic proteins has been identified as a risk factor for unwanted immunogenicity. ${ }^{1-11}$ These particles can be composed of protein and/or foreign materials that may be introduced during manufacturing or shed into formulations from product storage containers. For example, particles composed of foreign material including glass flakes shed from glass vials and stainless steel microparticles

eroded from filler pumps have been found in drug products. ${ }^{12,13}$ Studies conducted in mice have shown that glass particles or stainless steel particles in protein formulations can act as adjuvants and enhance antibody responses against co-administered proteins. ${ }^{14-16}$

Silicone oil microdroplets are another type of sub-visible particle found in protein formulations. Silicone oil is the lubricant typically used in glass prefilled syringes in order to allow smooth movement of the plunger through the syringe during administration to patients. ${ }^{17}$ Prefilled syringes are commonly used for storage and delivery of therapeutic protein products. Their reduced handling requirements, ease of administration, reduced risk of contamination, and elimination of the need for overfill make prefilled syringes a popular choice among producers and consumers. ${ }^{17,18}$ Because prefilled syringes function as a storage container as well as a delivery device, therapeutic proteins within these syringes are exposed to silicone oil for their entire shelf life. ${ }^{19}$ During storage, shipping, and administration to the patient, silicone oil can be shed from the syringe barrel wall, forming microdroplets of silicone oil within the protein formulation. $^{18,20}$

Silicone oils are also used in breast implants. Breast implants are constructed of an outer shell made of silicone elastomer and a silicone oil filler material. ${ }^{21}$ Breast implant augmentation and reconstruction is the second most common plastic surgery procedure in the United States, 
with over 280,000 surgeries conducted in $2014 .{ }^{22}$ Silicone-filled breast implants may rupture or leak, releasing silicone oil microdroplets to the surrounding tissue. Concerns persist that rupture or leakage of silicone oil from breast implants may induce autoimmune responses in patients. ${ }^{23}$

The instability of proteins in the presence of silicone oil has been a concern in the biopharmaceutical industry for decades. ${ }^{24-26}$ Studies have shown that proteins of many types readily adsorb to silicone oil including monoclonal antibodies, fusion proteins, and enzymes. ${ }^{27-31}$ Silicone oil may cause protein aggregation and/or perturbations in protein structure. ${ }^{27-29,31-33}$ Also, visible particulates have been observed in protein formulations stored in siliconized syringes. $^{31,34,35}$

It is unknown whether protein instability in the presence of silicone oil might increase the risk of immunogenicity. However, insights may be gained from studies on vaccines. In vaccine formulations, particulate adjuvants that adsorb antigen are regularly added in order to increase immunogenicity of the antigen. ${ }^{36}$ Two common vaccine adjuvants are Freund's adjuvant and MF59, which are both emulsions composed of oil and water and include surfactant for stabilization. Complete Freund's adjuvant (CFA) and incomplete Freund's adjuvant (IFA) contain high oil contents and are only approved for use in animal models. MF59 is an oil-inwater emulsion that was approved for use in humans in Europe and is found in several vaccines, including the influenza vaccine. ${ }^{37}$ We hypothesize that the silicone oil microdroplets present in therapeutic protein formulations may act in a fashion similar to that of these oil-based vaccine adjuvants and augment immune responses to administered proteins.

Several animal studies have been conducted to examine the effects of silicone oil microdroplets on the immunogenicity of proteins. In these studies, the proteins tested were recognized as foreign to the animal model used. In the 1990's, a study showed that antibody 
responses in rats injected with a bovine serum albumin (BSA) solution containing silicone oil were stronger than antibody responses in mice injected with a silicone oil-free BSA solution. ${ }^{38}$ Recently, a study found that mice injected with ovalbumin formulations containing silicone oil microdroplets elicited robust antibody responses against ovalbumin; the adjuvant effect of the added silicone oil was equivalent to that of aluminum hydroxide, the common microparticlebased vaccine adjuvant. ${ }^{39}$ Another study reported that BALB/c mice (which do not produce IgG2c antibodies) exhibited enhanced immune responses when the mice were injected with a murine monoclonal $\operatorname{IgG} 2 \mathrm{c}$ antibody in a formulation that contained silicone oil microdroplets. ${ }^{40}$

Many therapeutic proteins are engineered to be identical to their endogenous counterparts and thus might not be expected to be immunogenic. However, even these protein products can cause adverse immune response in patients and result in production of anti-drug antibodies (ADAs). ${ }^{41,42}$ ADAs may decrease the efficacy of the drug product and/or induce severe side effects in patients. ${ }^{42,43}$ Antibody formation in patients has been reported for a number of recombinant therapeutic protein products on the market, including recombinant human insulin, recombinant human growth hormone, recombinant interferon-beta, and anti-tumor necrosis factor-alpha monoclonal antibodies such as adalimumab and infliximab. ${ }^{44-51}$ As discussed above, silicone oil microdroplets can act as an adjuvant to elicit antibody responses against foreign proteins, but it is unknown whether their presence in formulations of therapeutic proteins with less inherent immunogenicity -such as recombinant proteins that are nominally identical to endogenous proteins- can produce a similar adjuvant response.

In this study, we investigated the capability of silicone oil microdroplets to induce an antibody response in mice against recombinant murine growth hormone (rmGH). Murine growth hormone is produced constitutively in mice, and thus the nominally identical rmGH would be 
expected to be immunologically well-tolerated in mice. In Study 1, we measured antibody responses in mice to two injections of $\mathrm{rmGH}$ formulations that contained silicone oil microdroplets. The second injection was administered two weeks after the first injection. In Study 2, we measured antibody responses in mice after daily injections of rmGH formulations containing silicone oil microdroplets. We also monitored changes in antibody responses at later time points after additional injections of the formulations to mice for Study 2. Immune responses were characterized by measuring antibodies against rmGH in mouse serum using enzyme-linked immunosorbent assays (ELISAs).

Characterization of formulations included size-exclusion high-performance liquid chromatography (SE-HPLC) to determine the fraction of rmGH adsorbed to silicone oil microdroplets and soluble aggregate levels within the formulations. Endotoxin levels in samples prepared for injection were measured. Particle concentrations in formulations were monitored with microflow digital imaging. Tertiary structure changes in rmGH adsorbed to silicone oil microdroplets were examined using intrinsic fluorescence quenching.

\section{MATERIALS AND METHODS}

\section{Materials}

Medical grade silicone oil (Dow Corning ${ }^{\circledR} 360,1000 \mathrm{cSt}$ ) was purchased from Nexeo Solutions (Denver, Colorado). Chemicals obtained from Sigma Aldrich (St. Louis, Missouri) included sodium phosphate monobasic, sodium phosphate dibasic, MES hydrate, glycerol, Antifoam 204, chloramphenicol, dithiothreitol (DTT), ethylenediaminetetraacetic acid (EDTA), and bovine serum albumin (BSA). Materials purchased from Fisher Scientific (Waltham, Massachusetts) included acrylamide, urea, ampicillin sodium salt, isopropyl $\beta$-D-1thiogalactopyranoside (IPTG), reduced glutathione, sodium chloride, sodium hydroxide, tris, 
Tween $20^{\circledast}, 10 \mathrm{x}$ phosphate buffered saline (PBS), sulfuric acid, HyClone ${ }^{\mathrm{TM}}$ water for injection (WFI), and microhematocrit capillary tubes for mouse blood collection. Acetic acid and hexanes (95\% n-hexane) were from Avantor Performance Materials (Center Valley, Pennsylvania). Yeast extract was purchased from Becton Dickinson and Company (Franklin Lakes, New Jersey). EMPROVE $^{\circledR}$ sucrose and $33 \mathrm{~mm}$ diameter syringe filters with $0.22 \mu \mathrm{m}$ pore size PVDF membranes were purchased from EMD Millipore (Billerica, Massachusetts). Toyopearl Super Q650M resin was purchased from Tosoh Bioscience (King of Prussia, PA) and packed in a XK 50 column (GE Healthcare Bio-Sciences, Piscataway, New Jersey). Phenyl Sepharose ${ }^{\mathrm{TM}}$ High Performance resin was purchased from Fisher Scientific (Waltham, Massachusetts) and packed in a XK 26 column (GE Healthcare Bio-Sciences, Piscataway, New Jersey). Amicon Ultra-15 centrifugal filter units containing an Ultracel regenerated cellulose membrane with 10,000 kDa NMWL were also purchased from EMD Millipore (Billerica, Massachusetts).

For Study 1, peroxidase goat anti-mouse $\operatorname{IgG} 1, \operatorname{IgG} 2 \mathrm{a}, \operatorname{IgG} 2 \mathrm{~b}, \operatorname{IgG} 2 \mathrm{c}$, and $\operatorname{IgM}$ were purchased from Jackson ImmunoResearch Laboratories, Inc. (West Grove, Pennsylvania), and peroxidase-conjugated goat anti-mouse IgG3 was purchased from Life Technologies (Grand Island, New York). For Study 2, goat anti-mouse IgG1, IgG2a, IgG2b, IgG3, IgM, and horse radish peroxidase conjugated rabbit polyclonal to goat IgG were purchased from Abcam (Cambridge, United Kingdom).

For both studies, 1-Step ${ }^{\mathrm{TM}}$ Ultra TMB and Immulon ${ }^{\circledR} 4 \mathrm{HBX} 96$ well plates were obtained from Thermo Scientific (Waltham, Massachusetts). Non-siliconized HSW Norm-Ject ${ }^{\circledR}$ sterile 1 $\mathrm{mL}$ syringes (Henke Sass Wolf, Tuttlingen, Germany) were used for injections through $\mathrm{BD}^{\mathrm{TM}}$ 25G 5/8 inch sterile needles (Becton Dickinson and Company, Franklin Lakes, New Jersey) and non-siliconized HSW Norm-Ject ${ }^{\circledR}$ sterile $10 \mathrm{~mL}$ syringes were used for sample preparation. 
Goldenrod $^{\mathrm{TM}}$ animal lancets were obtained from Braintree Scientific, Inc. (Braintree, Massachusetts). Acrodisc ${ }^{\circledR}$ unit with a Mustang ${ }^{\circledR}$ E membrane were purchased from Pall Corp. (Port Washington, New York)

\section{Expression and Purification of rmGH}

rmGH was expressed in E.coli and purified as described previously ${ }^{52}$, with minor modifications. A Rosetta-DE3 E.coli strain that contained a pET21a+/mGH plasmid was stored at $-80^{\circ} \mathrm{C}$ until use. The E.coli cells were inoculated in $3 \mathrm{~mL}$ of enriched media that contained 100 $\mathrm{mM}$ MES (pH 6.5), 4\% (w/v) yeast extract, 1\% (w/v) sodium chloride, 1\% (v/v) glycerol, 50 $\mu \mathrm{g} / \mathrm{mL}$ chloramphenicol, $50 \mu \mathrm{g} / \mathrm{mL}$ ampicillin and $0.01 \%$ (v/v) Antifoam 204. The $3 \mathrm{~mL}$ culture was incubated overnight in a shaker at $275 \mathrm{rpm}$ and at $37^{\circ} \mathrm{C}$ in a $10 \mathrm{~mL}$ sterile tube. The next day, the $3 \mathrm{~mL}$ culture was transferred into a $250 \mathrm{~mL}$ baffled flask that contained $25 \mathrm{~mL}$ of enriched media. The $25 \mathrm{~mL}$ cell culture was incubated in a shaker at $275 \mathrm{rpm}$ for $2 \mathrm{~h}$ at $37^{\circ} \mathrm{C}$. Next, the cell culture was transferred into $3 \mathrm{~L}$ of the enriched media in a BioFlo® 110 fermenter (New Brunswick Scientific Co., Edison, New Jersey) with controlled temperature, pH, and dissolved oxygen. The $\mathrm{pH}$ was controlled by addition of $3 \mathrm{M}$ hydrogen chloride or $2 \mathrm{M}$ sodium hydroxide. The optical density of the cell culture was measured at $600 \mathrm{~nm}$ using a Lambda 35 UV/VIS spectrometer (PerkinElmer Instruments, Waltham, Massachusetts).

When the cell culture reached the desired optical density between 5 and 10, expression of rmGH was induced by addition of isopropyl $\beta$-D-1-thiogalactopyranoside (IPTG) to $0.75 \mathrm{mM}$. After an induction period of $3 \mathrm{~h}$, cells were harvested by centrifugation at 4,500 rpm for $20 \mathrm{~min}$. Cell pellets were resuspended in lysis buffer that contained $50 \mathrm{mM}$ tris ( $\mathrm{pH} 8.0), 50 \mathrm{mM} \mathrm{NaCl}, 1$ mM EDTA and $1 \mathrm{mM}$ DTT. Cells were lysed by two passes through a high pressure 
homogenizer (GEA Niro Soavi, Panda Plus, Columbia, Maryland) at a pressure of 800 to 1,000 bar. After cell lysis, inclusion bodies that consisted of large insoluble aggregates of rmGH were collected by centrifugation at $15,000 \mathrm{~g}$ for $40 \mathrm{~min}$ at $20^{\circ} \mathrm{C}$. The supernatant was discarded, and the pellet that contained inclusion bodies was resuspended in sterile water and stored at $-80^{\circ} \mathrm{C}$.

Inclusion bodies were solubilized and rmGH was refolded at a protein concentration of 1 $\mathrm{mg} / \mathrm{mL}$ (determined by SDS-PAGE densitometry) in a buffer containing $100 \mathrm{mM}$ tris (pH 9.0), 2 $\mathrm{M}$ urea and $0.5 \mathrm{mM}$ reduced glutathione. To foster protein disaggregation and refolding, the suspension of inclusion bodies was incubated at $200 \mathrm{MPa}$ for 12-16 hours overnight in a PreEMT $^{\mathrm{TM}}$ E150 high-pressure protein refolding apparatus (BaroFold Inc., Boulder, Colorado).

After pressure treatment, solubilized and refolded $\mathrm{rmGH}$ was purified using anion exchange chromatography followed by hydrophobic interaction chromatography. The solution that contained soluble rmGH and host cell proteins was loaded onto a $100 \mathrm{~mL}$ Toyopearl@ Super Q 650M column that was equilibrated in Buffer A composed of $20 \mathrm{mM}$ tris ( $\mathrm{pH} 8.0)$ at a flow rate of $2 \mathrm{~mL} / \mathrm{min}$. rmGH was eluted from the column using a 100 min linear gradient at a flow rate of $5 \mathrm{~mL} / \mathrm{min}$ of Buffer A to Buffer B, which was composed of $40 \mathrm{mM}$ tris (pH 8.0), $0.5 \mathrm{M}$ $\mathrm{NaCl}$ and $0.4 \mathrm{M}$ urea. Fractions were collected every 2 minutes in $10 \mathrm{~mL}$ glass tubes and analyzed using SDS-PAGE. Fractions that contained only monomeric and aggregated rmGH were pooled and prepared for hydrophobic interaction chromatography. $\mathrm{NaCl}$ was added to the pooled fractions to achieve a final concentration of $2 \mathrm{M}$, and the solution was loaded onto a Phenyl Sepharose ${ }^{\mathrm{TM}}$ High Performance column that was equilibrated in buffer that contained 20 $\mathrm{mM}$ sodium phosphate ( $\mathrm{pH} 7.4$ ) and $2 \mathrm{M} \mathrm{NaCl}$. rmGH was eluted from the column using a 30 min linear gradient to sterile buffer composed of $20 \mathrm{mM}$ sodium phosphate $(\mathrm{pH}$ 7.4) at a flow rate of $5 \mathrm{~mL} / \mathrm{min}$. Fractions were collected every 2 minutes in $10 \mathrm{~mL}$ glass tubes and analyzed 
using SDS-PAGE. Final fractions that contained purified monomeric rmGH in $20 \mathrm{mM}$ sodium phosphate (pH 7.4) were pooled.

Lastly, purified $\mathrm{rmGH}$ was concentrated and filtered before storage at $-80^{\circ} \mathrm{C}$. First, the pooled rmGH solution was centrifuged at $4,000 \mathrm{~g}$ for $10 \mathrm{~min}$ at $4^{\circ} \mathrm{C}$ to remove particulates. Next, $15 \mathrm{~mL}$ of the rmGH solution was added to each Amicon Ultra-15 centrifugal filter unit that contained an Ultracel regenerated cellulose membrane with 10,000 kDa NMWL. Centrifugation was performed at $4,000 \mathrm{~g}$ for $15 \mathrm{~min}$ at $4^{\circ} \mathrm{C}$, and retentate containing concentrated rmGH solution at $0.5-1.0 \mathrm{mg} / \mathrm{mL}$ was transferred to a separate tube. Concentrated rmGH solution was then drawn into $10 \mathrm{~mL}$ non-siliconized sterile syringes without a needle attached and filtered through a $33 \mathrm{~mm}$ diameter syringe filter with a $0.22 \mu \mathrm{m}$ pore size PVDF membrane. rmGH stock solution was stored in $0.5 \mathrm{~mL}$ aliquots in $1.5 \mathrm{~mL}$ polypropylene microcentrifuge tubes at $-80^{\circ} \mathrm{C}$ until further use. Purified rmGH was thawed and analyzed by SE-HPLC and circular dichroism spectroscopy. SE-HPLC data and circular dichroism spectra collected were similar to results previously published for rmGH in Fradkin et al. ${ }^{52}$

\section{Sample Preparation (rmGH)}

Aliquots of rmGH stock solution in $20 \mathrm{mM}$ sodium phosphate buffer ( $\mathrm{pH} 7.4$ ) were thawed at room temperature and centrifuged at $5,000 \mathrm{~g}$ for $5 \mathrm{~min}$ at $4^{\circ} \mathrm{C}$ to remove particulates. Endotoxin was removed from rmGH solutions using an Acrodisc $®$ unit with a Mustang® E membrane using a syringe at $1 \mathrm{~mL} / \mathrm{min}$. Endotoxin levels in prepared solutions were determined using a QCL $1000^{\mathrm{TM}}$ Limulus Amebocyte Lysate test kit (LONZA, Basel, Switzerland). Samples for injection into mice were prepared by filtration and ultracentrifugation as previously described in Chisholm et al. ${ }^{39} \mathrm{rmGH}$ concentration was determined by measurement of the absorbance at 
$280 \mathrm{~nm}$ using a PerkinElmer Lambda 35 UV/VIS spectrometer (Waltham, Massachusetts) and the extinction coefficient of $0.73 \mathrm{~mL} /(\mathrm{mg} \cdot \mathrm{cm})$.

\section{Preparation of Silicone Oil Emulsions}

Silicone oil emulsions were prepared using two techniques. "High concentration" silicone oil emulsions were created by passage of a 5\% (v/v) silicone oil in deionized water mixture through an Emulsiflex ${ }^{\mathrm{TM}} \mathrm{C} 5$ high pressure homogenizer (Avestin, Inc., Ottawa, Canada). The protocol followed was previously described in Chisholm et al. ${ }^{39}$ Silicone oil emulsions that contained lower amounts of silicone oil that were approximately equivalent to the amounts found in commercial siliconized syringes, were created directly from commercially-available siliconized syringes and are referred to as "low concentration" silicone oil emulsions. BD LoDose $^{\mathrm{TM}}$ U-100 insulin syringes (Becton-Dickinson, Franklin Lakes, New Jersey) were filled with $20 \mathrm{mM}$ sodium phosphate buffer ( $\mathrm{pH}$ 7.4) containing 9\% (w/v) sucrose and were sonicated for 2 $\mathrm{h}$ using a Branson 3510 sonicator (Danbury, Connecticut) as described previously. ${ }^{39}$

\section{Characterization of Silicone Oil Emulsions}

The concentration of silicone oil in the prepared emulsions and the particle size distributions of silicone oil droplets in the emulsions were determined. The silicone oil concentrations were measured using hexane extraction and analysis by Fourier transform infrared (FTIR) spectroscopy as described previously. ${ }^{39}$ Samples were prepared in triplicate and loaded onto a VariGATR ${ }^{\mathrm{TM}}$ crystal (Harrick Scientific Products Inc., Pleasantville, New York), and absorbance was measured at $1220-1300 \mathrm{~cm}^{-1}$ using a Nicolet 6700 FT-IR spectrometer and OMNIC 8.3 software (Thermo Scientific, Waltham, Massachusetts). Collected spectra were analyzed using GRAMS/AI software version 9.1 (Thermo Fisher Scientific Inc., Waltham, 
Massachusetts). Particle size distributions of silicone oil droplets in the emulsions were measured in triplicate by light scattering. A Beckman Coulter LS230 (Fullerton, California) was used to measure the particle size distribution of the "high concentration" silicone oil emulsion created using a high pressure homogenizer. The protocol was described previously in Ludwig et al. ${ }^{27}$ The "low concentration" silicone oil emulsion prepared in commercial syringes was too dilute for analysis with a Beckman Coulter LS230. Alternatively, particle size distributions were measured using a DynaPro Dynamic Light Scattering instrument (Wyatt/ ProteinSolutions, Dernbach, Germany) and analyzed using Dynamics V6 ${ }^{\mathrm{TM}}$ version 6.3.40 software (Proterion Corp., Piscataway, New Jersey) as described previously. ${ }^{39}$ The silicone oil surface area per volume of emulsion was calculated from the particle size distribution of silicone oil microdroplets and silicone oil concentration assuming spherical droplets.

\section{Adsorption of rmGH to Silicone Oil Microdroplets}

rmGH formulations containing silicone oil microdroplets were prepared as described in

Chisholm et al., ${ }^{39}$ with minor modifications. For Study 1, emulsions of silicone oil microdroplets were added to rmGH formulations in order to achieve a final $\mathrm{rmGH}$ concentration of $0.1 \mathrm{mg} / \mathrm{mL}$ in $20 \mathrm{mM}$ sodium phosphate buffer (pH 7.4) containing 9\% (w/v) sucrose. Formulations for Study 2 were prepared at $0.02 \mathrm{mg} / \mathrm{mL}$ rmGH in $20 \mathrm{mM}$ sodium phosphate buffer (pH 7.4). No surfactants were added to any formulations in these studies. To determine rmGH adsorption isotherms, samples at a total volume of $1 \mathrm{~mL}$ were prepared which contained $\mathrm{rmGH}$ at 0.1 $\mathrm{mg} / \mathrm{mL}$ and various concentrations of silicone oil emulsion. Formulations that contained $\mathrm{rmGH}$ and silicone oil microdroplets were rotated end-over-end at $8 \mathrm{rpm}$ for $1 \mathrm{~h}$ at room temperature to allow rmGH adsorption to the microdroplets. Also, oil-free rmGH formulations were rotated 
end-over-end and treated in an identical fashion as all other samples in order to serve as a control. The fraction of rmGH adsorbed to silicone oil microdroplets in each sample was determined using SE-HPLC as previously described. ${ }^{39}$

\section{Size-Exclusion High-Performance Liquid Chromatography}

The amounts of monomer and high molecular weight species (HMWS) in rmGH samples were determined by SE-HPLC. Following previously described methods, ${ }^{39}$ a TSKgel G3000SW $_{\mathrm{XL}}$ column (TOSOH Biosciences, Montgomeryville Pennsylvania) was used with a Beckman System Gold ${ }^{\circledR}$ HPLC (Beckman Coulter, Fullerton, California), System Gold ${ }^{\circledR} 168$ detector, and 32 Karat $^{\mathrm{TM}}$ analysis software. Chromatograms were analyzed in GRAMS/AI software version 9.1 (Thermo Fisher Scientific Inc., Waltham, Massachusetts).

\section{Particle Analysis (FlowCAM)}

Particle concentrations in formulations were measured using a microflow digital imaging technique, FlowCAM ${ }^{\circledR}$ (Fluid Imaging Technologies, Scarborough, Maine), as previously described. ${ }^{35}$ The instrument detects particles in the micron range between $2-100 \mu \mathrm{m}$. Triplicate measurements were made for each sample.

\section{Intrinsic Fluorescence Quenching of Adsorbed rmGH}

Tertiary structure changes in rmGH following adsorption to silicone oil microdroplets were examined using intrinsic fluorescence quenching of rmGH tryptophan residues. $\mathrm{rmGH}$ contains a single tryptophan (Trp) residue. Following previously described methods, ${ }^{29}$ a SLM Aminco Fluorimeter (SLM Instruments, Urbana, Illinois) was used to monitor the fluorescence 
intensity. Samples and controls included native rmGH, rmGH adsorbed to silicone oil microdroplets for 2 hours, rmGH adsorbed to silicone oil microdroplets for 1 week and rmGH unfolded in $8 \mathrm{M}$ urea with $25 \mathrm{mM}$ DTT. Samples were analyzed in triplicate. Data were graphed on a Stern-Volmer plot as previously described. ${ }^{39}$ The slope of all points in the plot was used to determine the Stern-Volmer constant $\left(\mathrm{K}_{\mathrm{sv}}\right)$ which indicates the relative accessibility of solvent to the single Trp residue in rmGH.

\section{Immunogenicity Testing in Animals}

Animal experiments described in protocol 1210.03 were approved by the University of Colorado Institutional Animal Care and Use Committee. Four or five mice were housed in each sterile, air-filtered cage with food and water available ad libitum. Mice were allowed to acclimate for a minimum of one week before the start of a study.

For Study 1, adult female CB6F1 (BALB/c x C57BL/6) mice of age greater than six weeks were purchased from Charles River Laboratories, Inc. (Wilmington, Massachusetts). Subcutaneous injections were administered to mice in the scruff of the neck on days 1 and 15 . Formulations were prepared the same day as injection. Samples were administered using nonsiliconized syringes, and each injection of $200 \mu \mathrm{L}$ contained $20 \mu \mathrm{g}$ of rmGH. Groups of eight mice were treated with formulations of $\mathrm{rmGH}, \mathrm{rmGH}$ that contained silicone oil microdroplets at a higher concentration of $3.7 \pm 0.5 \mathrm{mg} / \mathrm{mL}$, or $\mathrm{rmGH}$ that contained a lower concentration of $0.12 \pm 0.04 \mathrm{mg} / \mathrm{mL}$ silicone oil microdroplets extracted from commercial syringes. Also, control groups of mice were injected with buffer or with rmGH-free buffer that contained silicone oil microdroplets at $3.7 \pm 0.5 \mathrm{mg} / \mathrm{mL}$. Submandibular blood draws were performed before the start of the study to serve as a baseline for each mouse, as well as on day 11 and 29 to capture primary 
and secondary immune responses. Blood samples were collected in sterile microcentrifuge tubes that were then placed on ice. Subsequently, blood samples were centrifuged at 15,000 rpm for 10 min at $4^{\circ} \mathrm{C}$, and the serum supernatant was collected and stored in aliquots at $-80^{\circ} \mathrm{C}$ until further analysis.

For Study 2, adult female BALB/c mice greater than six weeks of age were purchased from Charles River Laboratories, Inc. (Wilmington, Massachusetts). Subcutaneous injections were administered daily to mice in the scruff of the neck on days 1 to 5 , days 8 to 12 , and days 15 to 19 . All formulations were prepared on day 1 and stored at $4{ }^{\circ} \mathrm{C}$ over the course of the study until they were injected into mice. Samples were administered using non-siliconized syringes, and each injection of $100 \mu \mathrm{L}$ contained $2 \mu \mathrm{g}$ of rmGH. Groups of eight mice were treated with formulations of buffer, buffer that contained silicone oil microdroplets at $1.16 \pm 0.04 \mathrm{mg} / \mathrm{mL}$, $\mathrm{rmGH}$, or $\mathrm{rmGH}$ that contained silicone oil microdroplets at $1.16 \pm 0.04 \mathrm{mg} / \mathrm{mL}$. A silicone oil concentration of $1.16 \mathrm{mg} / \mathrm{mL}$ was chosen which corresponds to a silicone oil microdroplet-to$\mathrm{rmGH}$ ratio of $0.45 \mathrm{~m}^{2} / \mathrm{mg}$ in order to have essentially no un-adsorbed $\mathrm{rmGH}$ remaining in solution. Silicone oil microdroplets for Study 2 were created using a high pressure homogenizer. Blood was collected from the retro-orbital venous sinus of each mouse using capillary tubes before the start of the study to serve as a baseline for each mouse, as well as on day 8 and 22 to capture primary and secondary immune responses. Again, blood samples were collected in sterile microcentrifuge tubes, which were then placed on ice and centrifuged as described above. Serum was obtained and stored in aliquots at $-80^{\circ} \mathrm{C}$ until further analysis. In the extended experimental duration for Study 2, mice were allowed a 2-week hiatus from injections after which five additional daily subcutaneous injections were administered at days 36 to 40 . Blood was collected at day 36,43 , and 50. 


\section{Anti-rmGH ELISA}

Antibodies specific to rmGH were measured using indirect ELISA. A similar protocol was followed to that published in Chisholm et al. ${ }^{39}$ Immulon $^{\circledR} 4 \mathrm{HBX}$ plates were coated with 5 $\mu \mathrm{g} / \mathrm{mL} \mathrm{rmGH}$ in $20 \mathrm{mM}$ tris at $\mathrm{pH} 8.5(100 \mu \mathrm{L} /$ well $)$ and incubated overnight at room temperature with gentle agitation. Plate wells were drained and then treated with blocking solution (PBS pH 7.4, 2\% BSA, $0.05 \%$ Tween $20 ®)$ for $1.5 \mathrm{~h}$. Next, plates were washed three times with wash buffer (PBS pH 7.4, 0.05\% Tween 20®). On a separate plate, serum samples were pretreated in $300 \mathrm{mM}$ acetic acid for $1 \mathrm{~h}$ and then the $\mathrm{pH}$ was adjusted to 7.4 with $1 \mathrm{M}$ tris buffer (pH 9.5). ${ }^{53}$ After acid treatment and $\mathrm{pH}$ adjustment, $50 \mu \mathrm{L}$ of each serum sample were transferred to the first row of the ELISA plate and serially diluted down the plate which contained $50 \mu \mathrm{L}$ of dilution buffer in each well (PBS pH 7.4, 2\% BSA, $0.05 \%$ Tween $20 \circledR$ ). After primary incubation for $1 \mathrm{~h}$, plates were washed five times with wash buffer. Next, secondary incubation was performed using two slightly different methods for the two animal studies. The CB6F1 (the F1 generation from a BALB/c x C57BL/6 cross) mouse strain used in Study 1 can produce both IgG2a and IgG2c immunoglobulin isotypes because the IgG2a immunoglobulin isotype is encoded by the parental BALB/c mouse strain and the IgG2c isotype is derived from the $\mathrm{C} 57 \mathrm{BL} / 6$ strain. The $\mathrm{BALB} / \mathrm{c}$ mouse strain cannot produce the $\mathrm{IgG} 2 \mathrm{c}$ isotype, and, therefore we did not test for the IgG2c isotype in the ELISAs conducted for Study

2. In Study 1, goat anti-mouse antibodies conjugated to horseradish peroxidase of subclass IgG1, IgG2a, IgG2b, IgG2c, IgG3, or IgM were diluted in blocking solution and used for secondary incubation as previously described. ${ }^{39}$ In Study 2, unconjugated goat anti-mouse antibodies of subclass IgG1, IgG2a, IgG2b, IgG3, IgM were diluted in blocking solution and used for secondary incubation for $1 \mathrm{~h}(50 \mu \mathrm{L} /$ well $)$. Plates were then washed five times with wash buffer. 
Next, horse radish peroxidase conjugated rabbit polyclonal antibody to goat IgG was diluted in blocking solution and added to the wells $(50 \mu \mathrm{L} /$ well $)$ for incubation for $1 \mathrm{~h}$.

For both Study 1 and Study 2, a final wash step was performed where plates were washed five times followed by addition of $50 \mu \mathrm{L}$ of TMB substrate solution to each well. After 25 min, $30 \mu \mathrm{L}$ of $0.5 \mathrm{M}$ sulfuric acid was added to each well to stop the reaction. Absorbance was measured at $450 \mathrm{~nm}$ using a $\operatorname{Vmax}^{\circledR}$ microplate reader (Molecular Devices Corporation, Sunnyvale, California). Absorbance values were converted into endpoint titers, which we defined as the reciprocal of the highest dilution that gave a signal above the cutoff value. Cutoff values for individual mice were calculated using a statistically defined endpoint titer determination method $^{54}$ and values for pretreatment blood drawn at day 0 from each mouse. For graphical presentation of the results, murine serum samples that were negative for antibodies were assigned an arbitrary titer value of one.

\section{Statistical Analysis}

SigmaPlot $^{\circledR} 12.2$ software (Systat Software Inc., San Jose, California) was used to perform statistical analyses. Nonparametric Mann-Whitney tests were performed to determine statistical differences in titer values between experimental groups. The sample size for each experimental group was equal to eight. Differences between experimental groups with p values less than 0.05 were considered significant.

\section{RESULTS}

\section{Characterization of Silicone Oil Emulsions}

The concentration of silicone oil in "high concentration" emulsions created with the high pressure homogenizer was determined by FTIR spectroscopy. Silicone oil emulsions used for 
Studies 1 and 2 contained $5.4 \pm 0.8 \mathrm{mg} / \mathrm{mL}$ and $8.7 \pm 0.3 \mathrm{mg} / \mathrm{mL}$ silicone oil, respectively, before dilution into rmGH formulations. "Low concentration" emulsions used for Study 1 were created by sonicating siliconized syringes and contained $0.16 \pm 0.05 \mathrm{mg} / \mathrm{mL}$ silicone oil before dilution into rmGH formulations. The particle size distributions of silicone oil microdroplets in the "low concentration" and "high concentration" emulsions were obtained by light scattering and were indistinguishable from those published in Chisholm et al. ${ }^{39}$ The mean diameter of silicone oil microdroplets in the emulsions was $0.13 \pm 0.04 \mu \mathrm{m}$.

\section{Characterization of rmGH Formulations containing Silicone Oil}

Figure 1 shows the fraction of rmGH adsorbed to silicone oil microdroplets as a function of silicone oil surface area per $\mathrm{mg}$ rmGH. As expected, the fraction of adsorbed rmGH increased as the surface area of silicone oil increased. A silicone oil microdroplet-to-rmGH ratio (surface area/mass) of $0.35 \mathrm{~m}^{2} / \mathrm{mg}$ was required to adsorb the majority of the soluble $\mathrm{rmGH}$ (fraction adsorbed greater than 0.95). No soluble HMWS were detected in oil-free rmGH formulations or rmGH formulations that contained silicone oil microdroplets at the various concentrations (data not shown). In Study 1, $0.1 \mathrm{mg} / \mathrm{mL}$ rmGH formulations prepared using "high concentration" silicone oil emulsions had a final silicone oil concentration of $3.7 \pm 0.5 \mathrm{mg} / \mathrm{mL}$, whereas $\mathrm{rmGH}$ formulations prepared with "low concentration" emulsions had a final silicone oil concentration of $0.12 \pm 0.04 \mathrm{mg} / \mathrm{mL}$. The fraction of rmGH adsorbed to silicone oil microdroplets in the "high concentration" or "low concentration" formulations were $0.82 \pm 0.08$ and $0.10 \pm 0.05$, respectively. In Study 2, formulations contained a lower concentration of rmGH at $0.02 \mathrm{mg} / \mathrm{mL}$. A sufficient amount of silicone oil microdroplets (corresponding to a silicone oil microdropletto-rmGH ratio of $0.45 \mathrm{~m}^{2} / \mathrm{mg}$ ) was added to $\mathrm{rmGH}$ formulations in order to have essentially no 
un-adsorbed rmGH remaining in solution. rmGH formulations contained silicone oil microdroplets at a final concentration of $1.16 \pm 0.04 \mathrm{mg} / \mathrm{mL}$ in Study 2 .

Particle concentrations in samples administered to mice in Study 1 were monitored using microflow digital imaging with FlowCAM®. Figure 2 shows that oil-free rmGH formulations contained $10^{3}-10^{4}$ particles $/ \mathrm{mL}$ in the $2-100$ micron size range. Particle concentrations in formulations that contained silicone oil microdroplets were two to four orders of magnitude higher than formulations of oil-free rmGH. Additionally, particle concentrations in $\mathrm{rmGH}$ formulations that contained silicone oil microdroplets did not change significantly during 1 week of storage at $4{ }^{\circ} \mathrm{C}$ (data not shown).

Figure 3 displays images taken using FlowCAM® that were used to evaluate morphologies of particles present in the formulations. In all formulations that contained silicone oil, the majority of the particles were spherical in shape and assumed to be silicone oil droplets. Most particles consisted of single droplets in suspension. For particles in formulations of rmGH that contained silicone oil, the droplets of silicone oil were presumably coated with adsorbed rmGH. A small fraction of particles in the formulations of rmGH that contained silicone oil were aspherical, and likely proteinaceous in nature.

In Study 1, endotoxin levels ${ }^{55}$ in the various formulations containing buffer, buffer and silicone oil microdroplets at high concentration, or buffer with $\mathrm{rmGH}$ were $0.1 \mathrm{EU} / \mathrm{mL}, 0.7$ $\mathrm{EU} / \mathrm{mL}$, and $0.1 \mathrm{EU} / \mathrm{mL}$, respectively. $\mathrm{rmGH}$ formulations that contained silicone oil microdroplets at high concentration or syringe-extracted silicone oil microdroplets at low concentration had endotoxin levels of $1.0 \mathrm{EU} / \mathrm{mL}$ and $0.2 \mathrm{EU} / \mathrm{mL}$, respectively. In Study 2, endotoxin levels in formulations of buffer and silicone oil microdroplets or buffer with rmGH were $0.1 \mathrm{EU} / \mathrm{mL}$ and $0.3 \mathrm{EU} / \mathrm{mL}$, respectively. 


\section{Detection of Tertiary Structure Changes in Adsorbed rmGH Using Intrinsic Fluorescence Quenching}

The Stern-Volmer plots for native rmGH, rmGH adsorbed to silicone oil microdroplets after 2 hours of incubation, rmGH adsorbed to silicone oil microdroplets after 1 week of incubation, and rmGH unfolded in $8 \mathrm{M}$ urea $25 \mathrm{mM}$ DTT are shown in Figure 4. The SternVolmer constant $\left(\mathrm{K}_{\mathrm{sv}}\right)$ reflects the relative accessibility of solvent to the Trp residue in rmGH. As

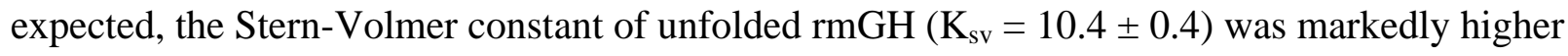
than that of native $\mathrm{rmGH}\left(\mathrm{K}_{\mathrm{sv}}=1.7 \pm 0.2\right)$, indicating a greater accessibility of solvent to Trp when rmGH is unfolded. When rmGH was incubated with silicone oil microdroplets for 2 hours or 1 week, the Stern-Volmer constants were similar $\left(\mathrm{K}_{\mathrm{sv}}=2.2 \pm 0.1\right.$ and $1.4 \pm 0.1$, respectively $)$ to that for native rmGH in the absence of silicone oil. The minimal changes in Stern-Volmer constants of incubated samples suggest that rmGH adsorbed to silicone oil retains near-native tertiary structure over time.

\section{Immunogenicity of rmGH Formulations Containing Silicone Oil}

$\underline{\text { Study } 1}$

In Study 1, mice were administered with formulations of buffer, buffer that contained silicone oil microdroplets, $\mathrm{rmGH}$, rmGH that contained a low concentration of silicone oil microdroplets, or rmGH that contained a high concentration of silicone oil microdroplets. Silicone oil microdroplets were added to rmGH formulations the same day as injection. As expected given that rmGH is a recombinant self-protein, no anti-rmGH antibodies were detected in mice injected with buffer, buffer that contained silicone oil or buffer with rmGH alone. Also, 
when administered with low or high concentrations of silicone oil microdroplets, $\mathrm{rmGH}$

formulations did not induce an anti-rmGH antibody response in mice. Anti-rmGH antibody titers were insignificant for $\operatorname{IgG} 1, \operatorname{IgG} 2 \mathrm{a}, \operatorname{IgG} 2 \mathrm{~b}, \operatorname{IgG} 2 \mathrm{c}, \mathrm{IgG} 3$, or IgM in mouse serum samples taken on day 11 and day 29 (data not shown). These results show that immunological tolerance to $\mathrm{rmGH}$ remained intact in mice administered once every other week with formulations of $\mathrm{rmGH}$ alone or rmGH with silicone oil microdroplets.

\section{$\underline{\text { Study } 2}$}

In Study 2, mice were given daily administrations of $\mathrm{rmGH}$ formulations that were oilfree or that contained silicone oil microdroplets. Table 1 shows the number of mice out of the total number of mice in each group showing anti-rmGH antibodies at day 22. Mice administered with rmGH alone did not produce an anti-rmGH antibody response in a significant number of mice, again indicating that the rmGH was recognized by the immune system as "self" and that immunological tolerance was intact. In contrast, half of the mice injected with rmGH formulations that contained silicone oil microdroplets produced antibodies against rmGH of the IgG1 subclass. Anti-rmGH IgG2a, IgG2b, IgG3, or IgM were not detected in a significant number of mice at day 22. Additional groups of mice were injected daily with rmGH-free control formulations of buffer or buffer that contained silicone oil microdroplets and, again as expected, did not produce an anti-rmGH antibody response. Figure 5 shows anti-rmGH IgG1 antibody titers for each mouse at day 22. Mice treated with rmGH formulations that contained silicone oil microdroplets exhibited low IgG1 antibody titers against rmGH which were significantly higher than antibody titers in mice treated with $\mathrm{rmGH}$ alone $(\mathrm{p}=0.032)$. No significant levels of antirmGH titers for IgG2a, IgG2b, IgG3 or IgM were detected at day 8 or day 22 (data not shown). 
Study 2 was extended to monitor changes in antibody response after additional daily injections administered on days 36 to 40 . No significant differences were detected in anti-rmGH IgG1, IgG2a, IgG2b, or IgG3 titers between day 22 and day 50. Interestingly, an IgM response was induced at later time points in mice treated with rmGH formulations that contained silicone oil microdroplets. Table 2 shows the number of mice out of the total number of mice in each group showing anti-rmGH IgM antibodies at days 8 through 50 treated with formulations of rmGH or rmGH that contained silicone oil microdroplets. Over half of the mice injected with rmGH formulations that contained silicone oil microdroplets produced an $\operatorname{IgM}$ response at later time points. Figure 6 shows that anti-rmGH IgM titers increased in mice administered with rmGH formulations that contained silicone oil microdroplets at day 43 and $50(\mathrm{p}=0.004, \mathrm{p}=$ 0.012) whereas mice treated with rmGH alone did not exhibit an increased IgM response.

\section{DISCUSSION}

In the abbreviated dosing regimen used in Study 1, immunological tolerance to rmGH was not broken and mice did not produce detectable anti-rmGH IgG or IgM antibodies when injected with formulations of $\mathrm{rmGH}$ alone or $\mathrm{rmGH}$ with silicone oil microdroplets, even at the

highest microdroplet concentration tested $(3.7 \pm 0.5 \mathrm{mg} / \mathrm{mL})$. In a previous study, ${ }^{39}$ formulations that contained a foreign protein, ovalbumin, and silicone oil microdroplets were prepared in a similar manner and administered to mice following an identical dosing regimen. Ovalbumin formulations that contained silicone oil microdroplets elicited a robust anti-ovalbumin antibody response in mice.

A well-known key factor that affects the immunogenicity of therapeutic protein products is the origin of the therapeutic protein, and whether the protein is recognized as self or foreign by the immune system. ${ }^{41,56}$ Aggregated forms of foreign therapeutic proteins may generate strong 
immune responses, whereas aggregated forms of therapeutic versions of endogenous proteins sometimes may not generate strong responses, depending on immunological tolerance to the endogenous protein. ${ }^{56}$ Likewise, we found that the ability of silicone oil microdroplets to act as adjuvants and augment antibody responses against administered proteins is highly dependent on the inherent immunogenicity of the protein of interest.

When mice were injected more frequently with formulations of rmGH that contained silicone oil microdroplets, immunological tolerance was broken and a weak antibody response was generated against the recombinant self-protein. In Study 2, mice were administered with rmGH formulations that contained silicone oil microdroplets at a lower concentration (1.16 \pm $0.04 \mathrm{mg} / \mathrm{mL}$ ) than in Study 1 and these mice produced an anti-rmGH IgG1 response. Levels of endotoxin in formulations for Study 1 and Study 2 were low and should not contribute to differences in immunogenicity. The fraction of rmGH adsorbed to silicone oil droplets was slightly higher in Study 2, which may affect the level of immune response. Still, our findings show that silicone oil microdroplets can act as an adjuvant and induce antibody responses against a recombinant self-protein, $r m G H$.

Immunological tolerance to rmGH was broken when mice were administered with formulations that contained silicone oil microdroplets in Study 2, but immunological tolerance was maintained in Study 1. The breakage in immunological tolerance observed in Study 2 could be due to the change in dosing regimen. Immunological tolerance was broken when the injection frequency was increased from a $20 \mu \mathrm{g}$ injection every other week to daily injections of $2 \mu \mathrm{g}$ each - a total of 5 injections per week. This dosing regimen of multiple injections per week at a lower dose was followed in order to mimic a typical daily dosing regimen $(0.3 \mathrm{mg} / \mathrm{kg} / \mathrm{week})$ used for patients treated with recombinant human growth hormone. ${ }^{57} \mathrm{~A}$ more frequent dosing schedule 
may increase immunogenicity of the therapeutic protein or promote a break in immunological tolerance. ${ }^{1,41}$ For example, a study with a recombinant interferon- $\beta$ therapeutic showed that $58 \%$ of multiple sclerosis patients produced ADAs when subcutaneously administered with interferon- $\beta$ once per week, whereas $89 \%$ of patients produced ADAs when injection frequency was increased to three times per week. ${ }^{58}$ Moreover, another study found that mice injected with a recombinant interferon- $\beta$ therapeutic twice per week exhibited higher antibody responses than mice injected with the therapeutic once per week. ${ }^{59}$ Increased injection frequency may increase antigen persistence. In humans, growth hormone has a very short half-life of 2 hours after subcutaneous administration. ${ }^{57}$ Therefore, the administered therapeutic version of growth hormone is not exposed to immune cells for long periods of time before clearance. Antigen persistence was presumably much higher in Study 2 when the injection frequency was increased to 5 times per week.

Alternatively, the increased immune response seen in Study 2 could perhaps have been due to silicone oil-induced changes in the rmGH structure during storage, because rmGH was incubated with silicone oil microdroplets for longer periods of time compared to Study 1. However, we discount this possibility because intrinsic fluorescence experiments showed that changes in tertiary structure of rmGH adsorbed to silicone oil microdroplets were minimal over the period of a week. Also, particle concentrations in rmGH formulations that contained silicone oil microdroplets did not change over the period of a week.

rmGH formulations used for Study 1 and Study 2 do not contain surfactant. Surfactants are commonly included in commercial formulations. Previous studies have shown that surfactant decreased the amount of protein adsorbed to silicone oil microdroplets for multiple proteins including bovine serum albumin, lysozyme, trastuzumab, abatacept, and albinterferon alpha. ${ }^{27,31}$ 
The amount of protein adsorbed to silicone oil microdroplets may or may not affect the immunogenicity of therapeutic protein formulations. In the vaccine literature, the relationship between the degree of protein adsorption and immunogenicity has been debated for decades. ${ }^{60-62}$ Although surfactant may decrease the amount of protein adsorbed, we cannot assume that decreased adsorption would necessarily correlate to decreased immune responses as oil-based vaccine adjuvants including MF59 and Freund's adjuvant contain surfactant and have a long history of eliciting potent immune responses. ${ }^{36,37}$ The current work does not allow us to determine the specific effect of surfactant on the adjuvant potential of silicone oil microdroplets in protein formulations.

The immune system can be activated through a T-cell-dependent B cell activation mechanism associated with production of $\mathrm{IgG} 1$ and/or T-cell-independent B cell activation mechanism associated with production of IgG3. ${ }^{63,64}$ The IgG1 response induced by $\mathrm{rmGH}$ formulations that contained silicone oil microdroplets is characteristic of a T-cell-dependent immune response in mice against a foreign protein antigen. Likewise, previous studies showed that silicone oil microdroplets in protein formulations that contained foreign protein also followed a T-cell-dependent mechanism. ${ }^{39} \mathrm{An} \mathrm{IgG3}$ response was not detected, suggesting that silicone oil microdroplets do not promote T-cell-independent antibody responses. As expected, silicone oil microdroplets did not induce an $\operatorname{IgG} 2 \mathrm{a}$ or $\mathrm{IgG} 2 \mathrm{~b}$ antibody response which are effective anti-pathogen immunoglobulin isotypes. ${ }^{65,66}$

The IgM isotype is the initial subclass produced by newly exposed B cells that have not undergone isotype switching. ${ }^{67}$ Typically during the antibody response to a protein antigen, isotype switching occurs approximately one week after injection at which point levels of IgM would presumably begin to decrease. As expected, mice did not produce anti-rmGH IgM 
antibodies at day 22, and instead produced anti-rmGH IgG1 antibodies indicating that class switching had occurred. Surprisingly, IgM was produced at later time points (day 43 and 50) in mice treated with rmGH formulations that contained silicone oil microdroplets after an additional week of injections. Mice administered with rmGH alone did not produce $\operatorname{IgM}$ at later time points. In another study, Shomali et al. ${ }^{15}$ also observed increased IgM levels at later times in mice subcutaneously injected with formulations of a murine monoclonal antibody adsorbed to glass microparticles. It is unclear why IgM antibodies appear against rmGH only at later time points. Perhaps, IgM was induced at later times due to a depot effect which is thought to increase antigen persistence at the site of injection. Filipe et al. ${ }^{68}$ studied the bio-distribution of fluorescently-labeled monomeric protein and aggregated protein after subcutaneous injection into mice. They found that monomeric protein dispersed rapidly from the site of injection, whereas aggregated protein in the micron size range remained at the site of injection for over a month. We speculate that rmGH-coated microdroplets of silicone oil may remain at the site of injection for longer periods of time than un-adsorbed $\mathrm{rmGH}$, thus allowing naïve B cells to be exposed to $\mathrm{rmGH}$ for extended periods of time and resulting in delayed secretion of IgM.

\section{CONCLUSION}

Silicone oil is used in as a lubricant in prefilled syringes as well as a filler material in breast implants. In these studies, we found that immunological tolerance to a recombinant selfprotein could be broken when formulations of rmGH that contained silicone oil microdroplets were administered daily to mice. Thus, silicone oil microdroplets can act as an immunological adjuvant and induce an antibody response against a recombinant self-protein. The adjuvant potency of silicone oil appears to be dependent on the inherent immunogenicity of the protein of interest, with more potent effects noted with foreign proteins. Furthermore, breakage of 
immunological tolerance to a recombinant self-protein may depend on the injection frequency used for administration of the therapeutic. During protein formulation development in prefilled syringes or development of breast implants, the immunogenicity risk of the product in the presence of silicone oil should be evaluated carefully.

\section{ACKNOWLEDGMENTS}

Funding was provided by NIH grant ROI EB006006 and the FDA Office of Women's Health. This project was supported in part by an appointment to the ORISE Research Participation Program with the Center for Drug Evaluation and Research, U.S. Food and Drug Administration, administered by the Oak Ridge Institute for Science and Education through an interagency agreement between the U.S. Department of Energy and FDA/Center. 


\section{REFERENCES}

1. Hermeling S, Crommelin DJA, Schellekens H, Jiskoot W. 2004. Structureimmunogenicity relationships of therapeutic proteins. Pharm Res 21:897-903.

2. Carpenter JF, Randolph TW, Jiskoot WIM, Crommelin DJA, Middaugh CR, Winter G, Fan Y, Kirshner S, Verthelyi D, Kozlowski S, Clouse KA, Swann PG, Rosenberg A, Cherney B. 2009. Overlooking subvisible particles in therapeutic protein products $\square$ : Gaps that may compromise product quality. J Pharm Sci 98:1201-1205.

3. Biro CE, Garcia G. 1965. The antigenicity of aggregated and aggregate-free human gamma-globulin for rabbits. Immunology 8:411-419.

4. Christian CL. 1960. Studies of aggregated gamma-globulin II. Effect in vivo. J Immunol $84: 117-121$.

5. Gamble CN. 1966. The role of soluble aggregates in the primary immune response of mice to human gamma globulin. Int Arch Allergy 30:446-455.

6. Ring J, Jesch F, Brendel W. 1977. Anaphylactoid reactions due to non-immune serum protein aggregates. Monogr Allergy 12:27-35.

7. Weksler ME, Bull G, Schwawrz GH, Stenzel KH, Rubin AL. 1970. Immunologic responses of graft recipients to antilymphocyte globulin: Effect of prior treatment with aggregate-free gamma globulin. J Clin Invest 49:1589-1595.

8. Fradkin AH, Carpenter JF, Randolph TW. 2009. Immunogenicity of aggregates of recombinant human growth hormone in mouse models. J Pharm Sci 98:3247-3264.

9. Joubert MK, Hokom M, Eakin C, Zhou L, Deshpande M, Baker MP, Goletz TJ, Kerwin BA, Chirmule N, Narhi LO, Jawa V. 2012. Highly aggregated antibody therapeutics can enhance the in vitro innate and late-stage T-cell immune responses. J Biol Chem 
$287: 25266-25279$.

10. Ahmadi M, Bryson CJ, Cloake EA, Welch K, Filipe V, Romeijn S, Hawe A, Jiskoot W, Baker MP, Fogg MH. 2015. Small amounts of sub-visible aggregates enhance the immunogenic potential of monoclonal antibody therapeutics. Pharm Res 32:1383-1394.

11. Rombach-Riegraf V, Karle AC, Wolf B, Sordé L, Koepke S, Gottlieb S, Krieg J, Djidja M-C, Baban A, Spindeldreher S, Koulov A V, Kiessling A. 2014. Aggregation of human recombinant monoclonal antibodies influences the capacity of dendritic cells to stimulate adaptive T-cell responses in vitro. PLoS One 9:1-17.

12. Tyagi AK, Randolph TW, Dong A, Maloney KM, Jr CH, Carpenter JF. 2009. IgG particle formation during filling pump operation $\square$ : A case study of heterogeneous nucleation on stainless steel nanoparticles. J Pharm Sci 98:94-104.

13. U.S. Food and Drug Administration. 2011. Advisory to Drug Manufacturers: Formation of Glass Lamellae in Certain Injectable Drugs. Available at: http://www.fda.gov/Drugs/DrugSafety/ucm248490.htm [Accessed April 3, 2015].

14. Fradkin AH, Carpenter JF, Randolph TW. 2011. Glass particles as an adjuvant: A model for adverse immunogenicity of therapeutic proteins. J Pharm Sci 100:4953-4964.

15. Shomali M, Freitag A, Engert J, Siedler M, Kaymakcalan Z, Winter G, Carpenter JF, Randolph TW. 2014. Antibody responses in mice to particles formed from adsorption of a murine monoclonal antibody onto glass microparticles. J Pharm Sci 103:78-89.

16. Van Beers MMC, Gilli F, Schellekens H, Randolph TW, Jiskoot W. 2012. Immunogenicity of recombinant human interferon beta interacting with particles of glass, metal, and polystyrene. J Pharm Sci 101:187-199.

17. Romacker M, Schoenknecht T, Forster R. 2008. The rise of prefilled syringes from niche 
product to primary container of choice: A short history. ONdrug Deliv. 4-5.

18. Jezek J, Darton NJ, Derham BK, Royle N, Simpson I. 2013. Biopharmaceutical formulations for pre-filled delivery devices. Expert Opin Drug Deliv 10:811-828.

19. Cleland J. 1993. The development of stable protein formulations: A close look at protein aggregation, deamidation, and oxidation. Crit Rev Ther Drug Carrier Syst 10:307-377.

20. Jenke DR. 2014. Extractables and leachables considerations for prefilled syringes. Expert Opin Drug Deliv 11:1591-1600.

21. Gampper TJ, Khoury H, Gottlieb W, Morgan RF. 2007. Silicone gel implants in breast augmentation and reconstruction. Ann Plast Surg 59:581-590.

22. The American Society for Aesthetic Plastic Surgery (ASAPS). 2014. Cosmetic Surgery National Data Bank Statistics. ASAPS , New York, NY.:

23. Hajdu SD, Agmon-Levin N, Shoenfeld Y. 2011. Silicone and autoimmunity. Eur J Clin Invest 41:203-211.

24. Chantelau E, Berger M. 1985. Pollution of insulin with silicone oil, a hazard of disposable plastic syringes. Lancet 1:1459.

25. Chantelau E, Berger M, Bohlken B. 1986. Silicone oil released from disposable insulin syringes. Diabetes Care 9:672-673.

26. Bernstein R. 1987. Clouding and deactivation of clear (regular) human insulin: Association with silicone oil from disposable syringes? Diabetes Care 10:786-787.

27. Ludwig DB, Carpenter JF, Hamel J, Randolph TW. 2010. Protein adsorption and excipient effects on kinetic stability of silicone oil emulsions. J Pharm Sci 99:1721-1733.

28. Britt KA, Schwartz DK, Wurth C, Mahler H, Carpenter JF, Randolph TW. 2012. Excipient effects on humanized monoclonal antibody interactions with silicone oil 
emulsions. J Pharm Sci 101:4419-4432.

29. Gerhardt A, Bonam K, Bee JS, Carpenter JF, Randolph TW. 2013. Ionic strength affects tertiary structure and aggregation propensity of a monoclonal antibody adsorbed to silicone oil - water interfaces. J Pharm Sci 102:429-440.

30. Thirumangalathu R, Krishnan S, Ricci MS, Brems DN, Randolph TW, Carpenter JF. 2009. Silicone oil- and agitation-induced aggregation of a monoclonal antibody in aqueous solution. J Pharm Sci 98:3167-3181.

31. Basu P, Blake-Haskins AW, O’Berry KB, Randolph TW, Carpenter JF. 2014. Albinterferon $\alpha 2 b$ adsorption to silicone oil-water interfaces: Effects on protein conformation, aggregation, and subvisible particle formation. J Pharm Sci 103:427-36.

32. Jones LS, Kaufmann A, Middaugh CR. 2005. Silicone oil induced aggregation of proteins. J Pharm Sci 94:918-27.

33. Basu P, Krishnan S, Thirumangalathu R, Randolph TW, Carpenter JF. 2013. IgG1 aggregation and particle formation induced by silicone-water interfaces on siliconized borosilicate glass beads $\square$ : A model for siliconized primary containers. J Pharm Sci 102:852-865.

34. Majumdar S, Ford BM, Mar KD, Sullivan VJ, Ulrich RG, D'souza AJM. 2011. Evaluation of the effect of syringe surfaces on protein formulations. J Pharm Sci 100:2563-2573.

35. Gerhardt A, Mcgraw NR, Schwartz DK, Bee JS, Carpenter JF, Randolph TW. 2014. Protein aggregation and particle formation in prefilled glass syringes. J Pharm Sci 103:1601-1612.

36. O'Hagan DT, De Gregorio E. 2009. The path to a successful vaccine adjuvant - "the long and winding road". Drug Discov Today 14:541-551. 
37. Israeli E, Agmon-Levin N, Blank M, Shoenfeld Y. 2009. Adjuvants and autoimmunity. Lupus 18:1217-1225.

38. Naim JO, Lanzafame RJ, Van Oss C. 1993. The adjuvant effect of silicone-gel on antibody formation in rats. Immunol Invest 22:151-161.

39. Chisholm CF, Nguyen BH, Soucie KR, Torres RM, Carpenter JF, Randolph TW. 2015. In vivo analysis of the potency of silicone oil microdroplets as immunological adjuvants in protein formulations. J Pharm Sci 104:3681-3690.

40. Shomali M, Tanriverdi S, Freitag AJ, Engert J, Winter G, Siedler M, Kaymakcalan Z, Carpenter JF, Randolph TW. 2015. Dose levels in particulate-containing formulations impact anti-drug antibody responses to murine monoclonal antibody in mice. J Pharm Sci 104:1610-1621.

41. Schellekens H. 2002. Immunogenicity of therapeutic proteins: clinical implications and future prospects. Clin Ther 24:1720-1740.

42. Sauerborn M, Brinks V, Jiskoot W, Schellekens H. 2010. Immunological mechanism underlying the immune response to recombinant human protein therapeutics. Trends Pharmacol Sci 31:53-59.

43. Shankar G, Pendley C, Stein KE. 2007. A risk-based bioanalytical strategy for the assessment of antibody immune responses against biological drugs. Nat Biotechnol 25:555-561.

44. Ahangari G, Ostadali M, Rabani A, J R, Sanati M, Zarindast M. 2004. Growth Hormone Antibodies Formation in Patients Treated with Recombinant Human Growth Hormone. J Immunopathol Pharmacol 17:33-38.

45. Fineberg SE, Galloway JA, Fineberg NS, Rathbun MJ, Hufferd S. 1983. Immunogenicity 
of recombinant DNA human insulin. Diabetologia 25:465-469.

46. Konrad MW, Childs AL, Merigan TC, Borden EC. 1987. Assessment of the antigenic response in humans to a recombinant mutant interferon beta. J Clin Immunol 7:365-375.

47. Karmiris K, Paintaud G, Noman M, Magdelaine-Beuzelin C, Ferrante M, Degenne D, Claes K, Coopman T, Van Schuerbeek N, Van Assche G, Vermeire S, Rutgeerts P. 2009. Influence of trough serum levels and immunogenicity on long-term outcome of adalimumab therapy in crohn's disease. Gastroenterology , Elsevier Inc. 137:1628-1640.

48. Jamnitski A, Bartelds GM, Nurmohamed MT, van Schouwenburg PA, van Schaardenburg D, Stapel SO, Dijkmans BAC, Aarden L, Wolbink GJ. 2011. The presence or absence of antibodies to infliximab or adalimumab determines the outcome of switching to etanercept. Ann Rheum Dis 70:284-288.

49. Radstake TRDJ, Svenson M, Eijsbouts AM, van den Hoogen FHJ, Enevold C, van Riel PLCM, Bendtzen K. 2009. Formation of antibodies against infliximab and adalimumab strongly correlates with functional drug levels and clinical responses in rheumatoid arthritis. Ann Rheum Dis 68:1739-1745.

50. Nanda KS, Cheifetz M, Moss AC. 2013. Impact of antibodies to infliximab on clinical outcomes and serum infliximab levels in patients with inflammatory bowel disease (IBD): A meta-analysis. Am J Gastroenterol 108:40-47.

51. O’Meara S, Nanda KS, Moss AC. 2014. Antibodies to infliximab and risk of infusion reactions in patients with inflammatory bowel disease: a systematic review and metaanalysis. Inflamm Bowel Dis 20:1-6.

52. Fradkin AH, Boand CS, Eisenberg SP, Rosendahl MS, Randolph TW. 2010. Recombinant murine growth hormone from E. coli inclusion bodies: expression, high-pressure 
solubilization and refolding, and characterization of activity and structure. Biotechnol Prog 26:743-749.

53. Patton A, Mullenix MC, Swanson SJ, Koren E. 2005. An acid dissociation bridging ELISA for detection of antibodies directed against therapeutic proteins in the presence of antigen. J Immunol Methods 304:189-95.

54. Frey A, Di Canzio J, Zurakowski D. 1998. A statistically defined endpoint titer determination method for immunoassays. J Immunol Methods 221:35-41.

55. Malyala P, Singh M. 2008. Endotoxin limits in formulations for preclinical research. J Pharm Sci 97:2041-2044.

56. Rosenberg AS. 2006. Effects of protein aggregates: An immunologic perspective. AAPS J 8:E501-507.

57. Genentech. 2014. Nutropin AQ Prescribing Information, San Francisco, CA.:

58. Ross C, Clemmesen KM, Svenson M, Srensen PS, Koch-Henriksen N, Skovgaard GL, Bendtzen K. 2000. Immunogenicity of interferon- $\beta$ in multiple sclerosis patients:

Influence of preparation, dosage, dose frequency, and route of administration. Ann Neurol 48:706-712.

59. Kijanka G, Jiskoot W, Schellekens H, Brinks V. 2013. Effect of treatment regimen on the immunogenicity of human interferon beta in immune tolerant mice. Pharm Res 30:15531560.

60. Gupta RK. 1998. Aluminum compounds as vaccine adjuvants. Adv Drug Deliv Rev 32:155-172.

61. Romero Méndez IZ, Shi Y, HogenEsch H, Hem SL. 2007. Potentiation of the immune response to non-adsorbed antigens by aluminum-containing adjuvants. Vaccine 25:825- 
833.

62. Clausi A, Cummiskey J, Merkley S, Carpenter JF, Braun LJ, Randolph TW. 2008.

Influence of particle size and antigen binding on effectiveness of aluminum salt adjuvants in a model lysozyme vaccine. J Pharm Sci 97:5252-5262.

63. Stevens T, Bossie A, Sanders V, Fernandez-Botran R, Coffman R, Mosmann T, Vitetta E. 1988. Regulation of antibody isotype secretion by subsets of antigen-specific helper T cells. Nature 334:255-258.

64. Snapper CM, McIntyre T, Mandler R, Pecanha LMT, Finkelman FD, Lees A, Mond JJ. 1992. Induction of IgG3 secretion by interferon gamma: A model for T cell-independent class switching in response to T cell-independent type 2 antigens. J Exp Med 175:13671371.

65. Coutelier J, van der Logt JTM, Heessen FWA, Warnier G, van Snick J. 1987. IgG2a restriction of murine antibodies elicited by viral infections. J Exp Med 165:64-69.

66. Nimmerjahn F, Ravetch J V. 2005. Divergent immunoglobulin g subclass activity through selective Fc receptor binding. Science 310:1510-1512.

67. Murphy K, Travers P, Walport M. 2008. Janeway’s immunobiology 7th ed., New York: Garland Science. p392-400.

68. Filipe V, Que I, Carpenter JF, Löwik C, Jiskoot W. 2014. In vivo fluorescence imaging of IgG1 aggregates after subcutaneous and intravenous injection in mice. Pharm Res 31:216227. 


\section{FIGURE LEGEND}

Figure 1. Fraction of rmGH adsorbed to silicone oil microdroplets as silicone oil surface area per $\mathrm{mg}$ rmGH increases. A silicone oil microdroplet-to-rmGH ratio (surface area/mass) of 0.35 $\mathrm{m}^{2} / \mathrm{mg}$ was needed to adsorb a fraction of greater than 0.95 . Error bars represent the standard deviation from the average of three replicates.

Figure 2. Particle concentrations in formulations of buffer, rmGH, buffer that contained emulsified silicone oil microdroplets, $\mathrm{rmGH}$ that contained emulsified silicone oil microdroplets, and $\mathrm{rmGH}$ that contained syringe-extracted silicone oil microdroplets. Particle concentrations were measured by FlowCAM ${ }^{\circledR}$ which detects particles between $2-100 \mu \mathrm{m}$ in the formulations that were injected into mice on day 1 (solid) and day 15 (striped) in Study 1. Particle concentrations were two to four orders of magnitude higher for formulations that contained silicone oil microdroplets compared to formulations of rmGH. Error bars represent the standard deviation from the average of three replicates.

Figure 3. An example of particles observed in formulations of buffer that contained silicone oil microdroplets (a) and formulations of rmGH that contained silicone oil microdroplets (b). Images were taken using microflow digital imaging with FlowCAM® which detects particles between $2-100 \mu \mathrm{m}$.

Figure 4. Stern-Volmer plots of inverse relative fluorescence vs. acrylamide concentration for native rmGH (black circles), rmGH adsorbed to silicone oil microdroplets for 2 hours (triangles), rmGH adsorbed to silicone oil microdroplets for 1 week (squares), and rmGH unfolded in $8 \mathrm{M}$ Urea $25 \mathrm{mM}$ DTT (diamonds). Stern-Volmer constants were obtained from the slope of the plot. Error bars represent the standard deviation from the average of three replicates.

Figure 5. Anti-rmGH IgG1 antibody titers for mice treated with formulations of buffer, buffer that contained silicone oil microdroplets, $\mathrm{rmGH}$, and $\mathrm{rmGH}$ that contained silicone oil microdroplets at day 22 in Study 2. Each data point represents the titer value of an individual mouse.

Figure 6. Anti-rmGH IgM antibody titers for mice treated with formulations of rmGH (a) and rmGH that contained silicone oil microdroplets (b) at day 8, 22, 36, 43, and 50 in Study 2. Each data point represents the titer value of an individual mouse. 
Figure 1

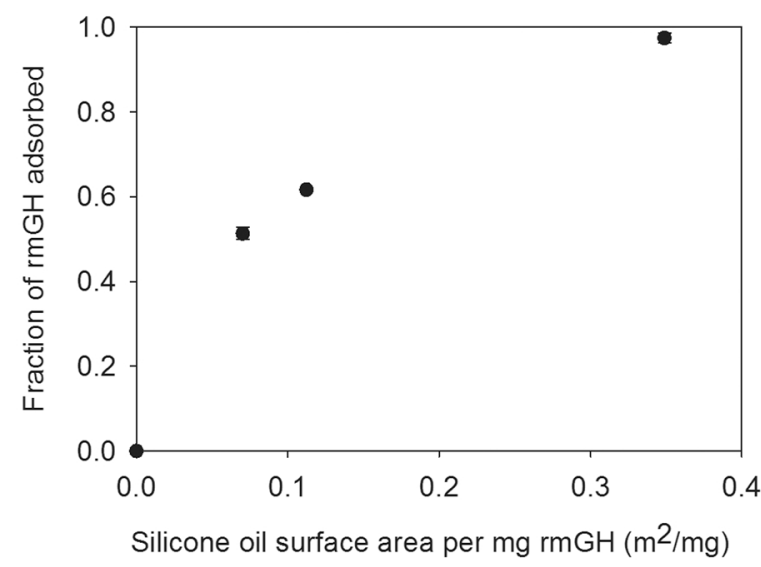


Figure 2

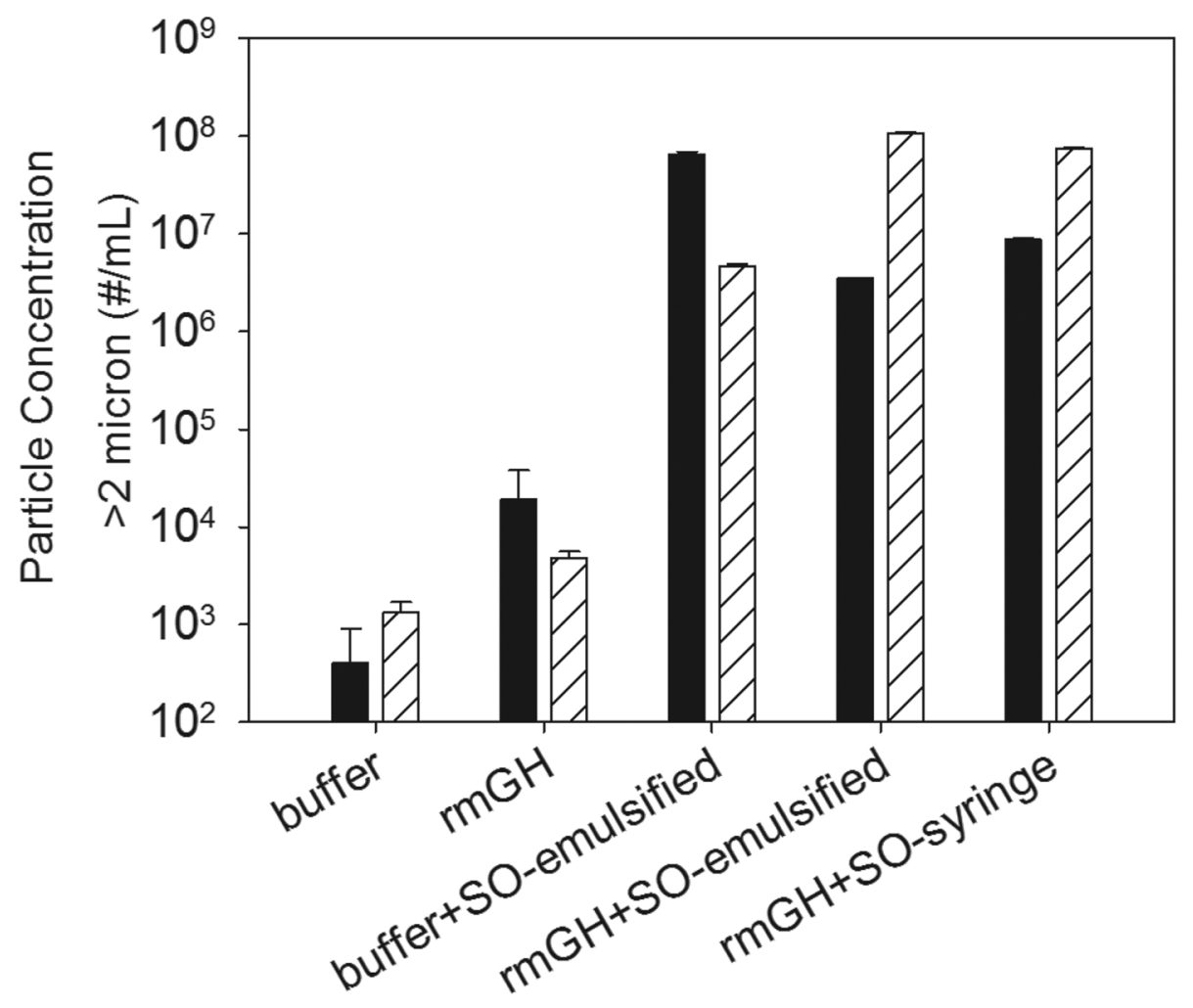


Figure 3

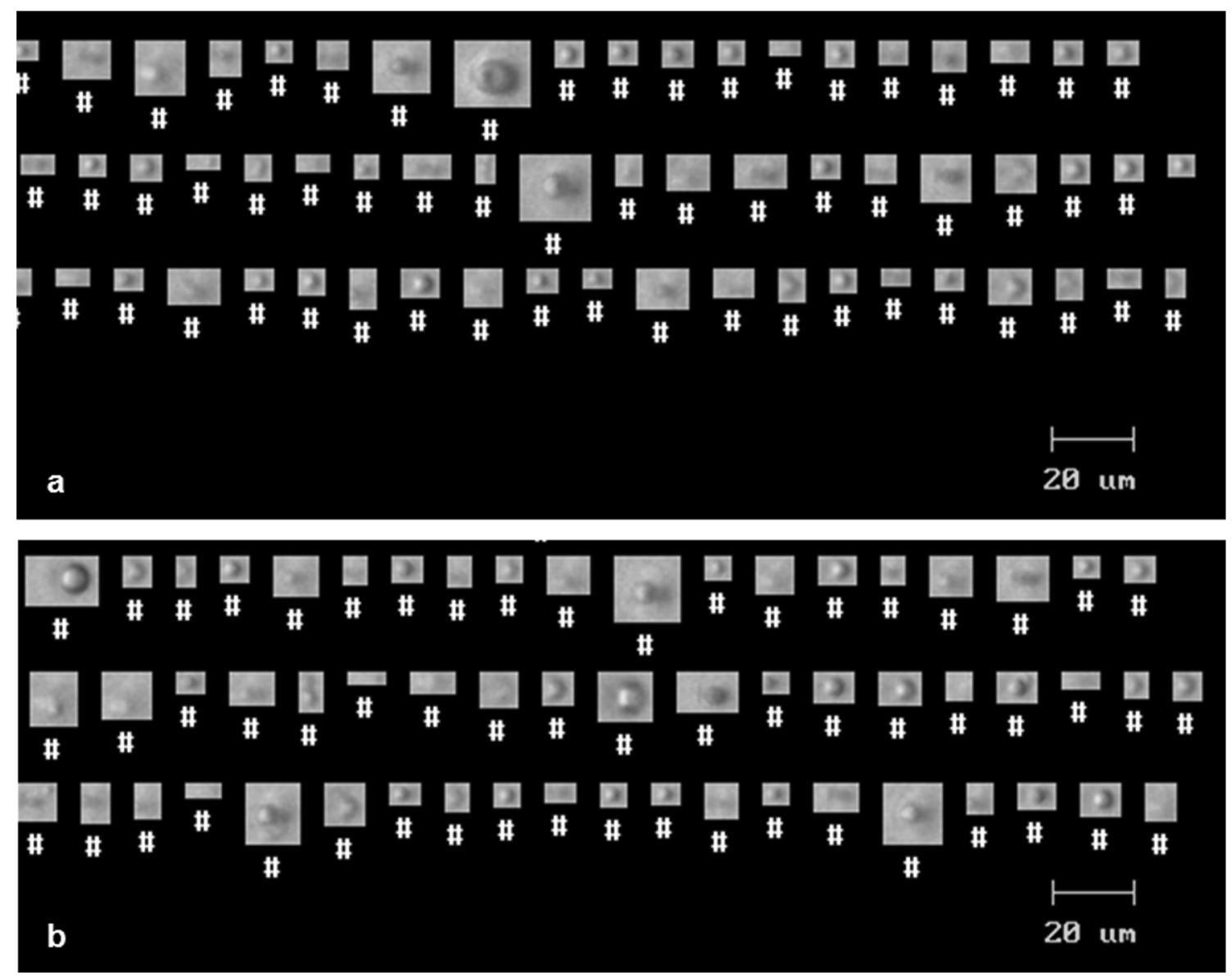


Figure 4

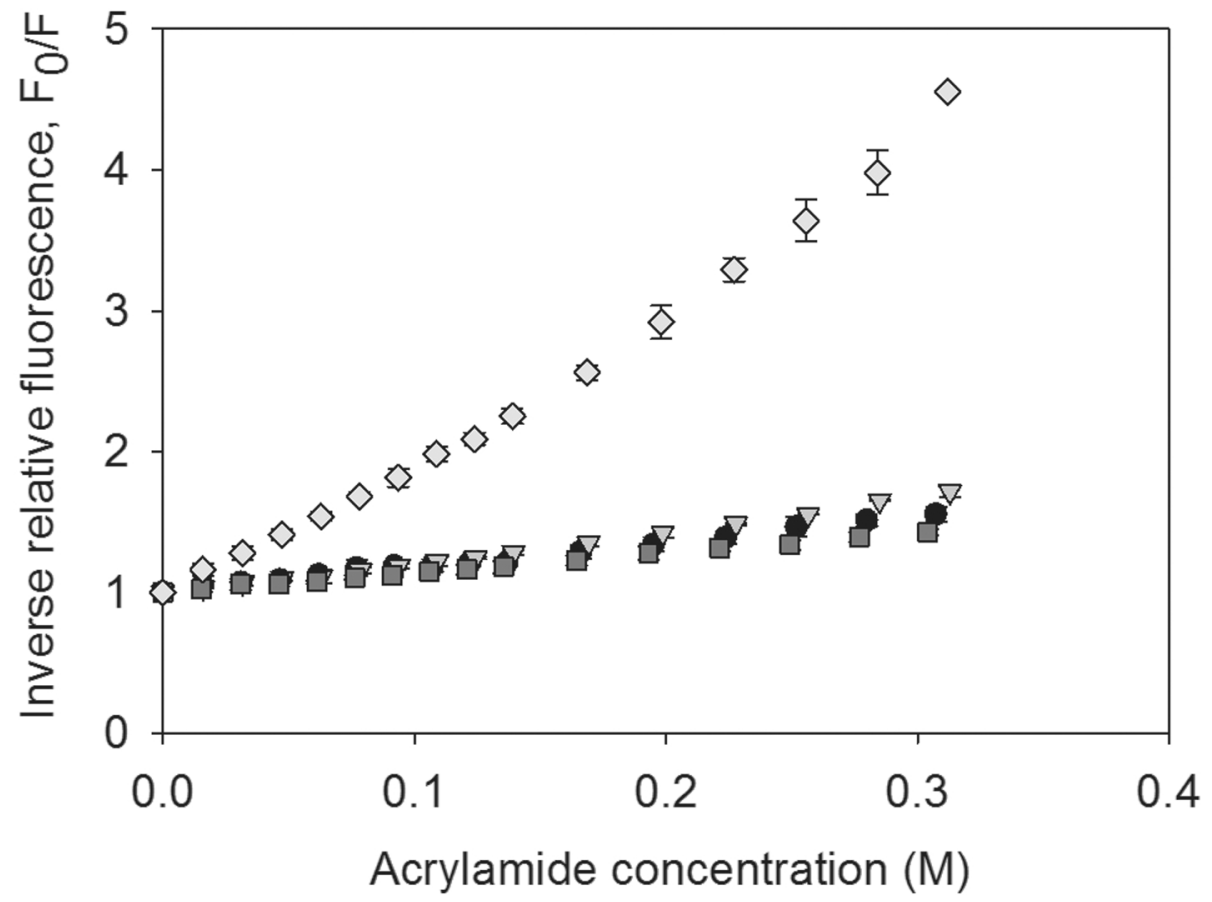


Figure 5

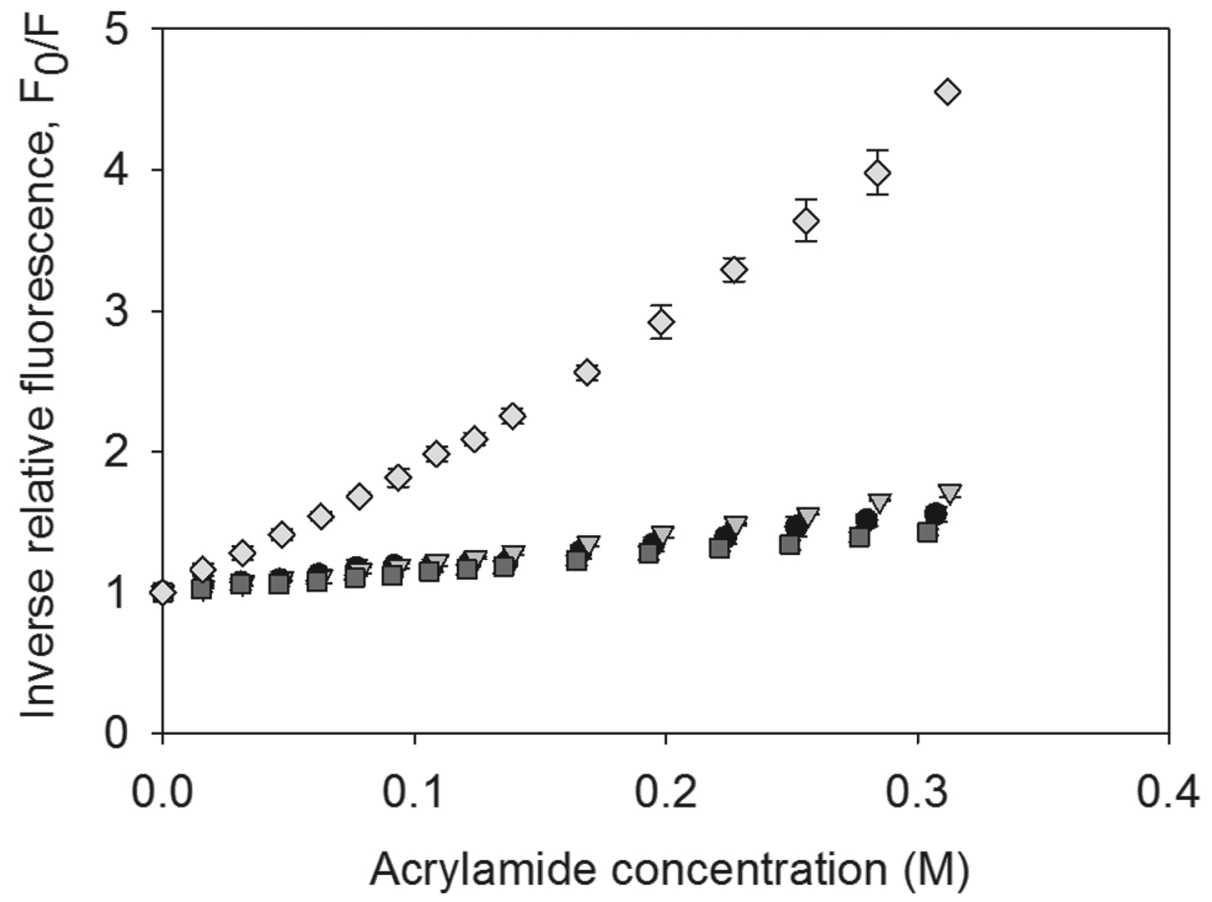


Figure 6

a

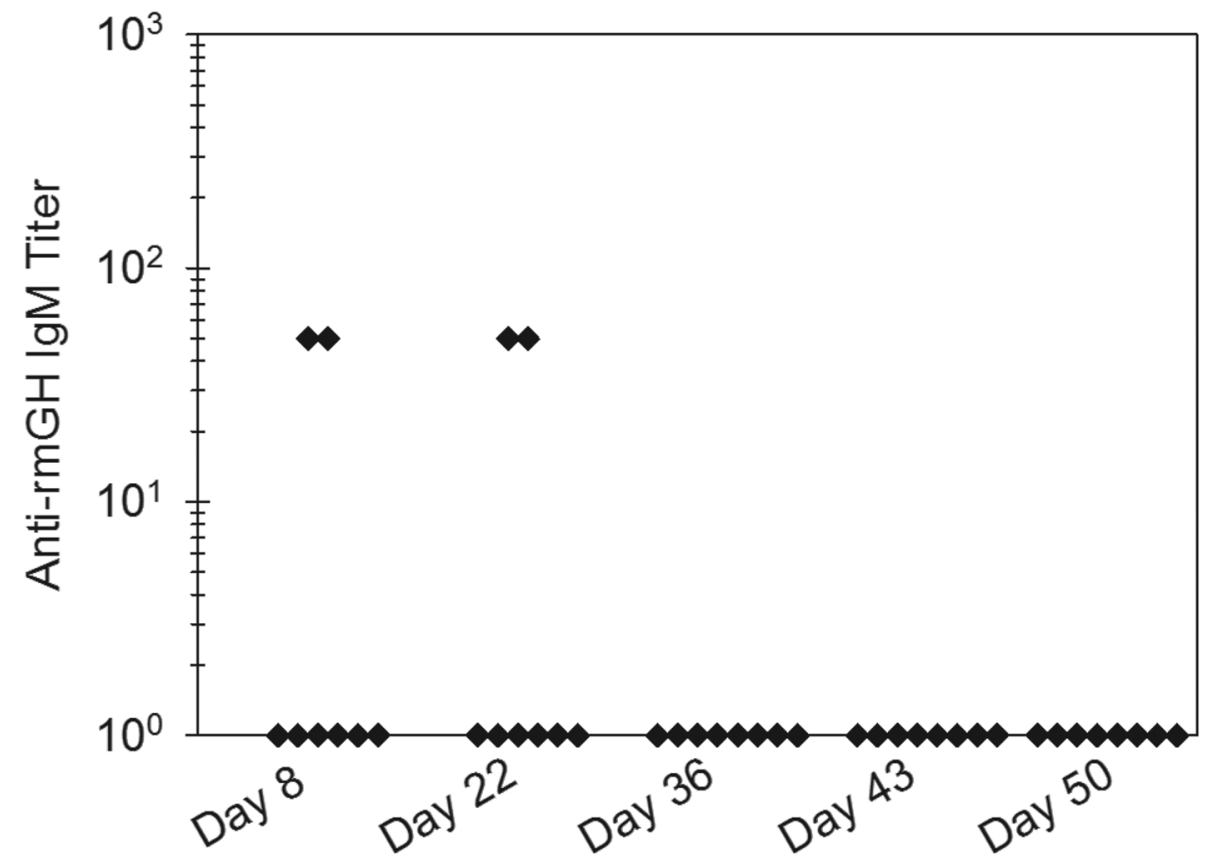

b

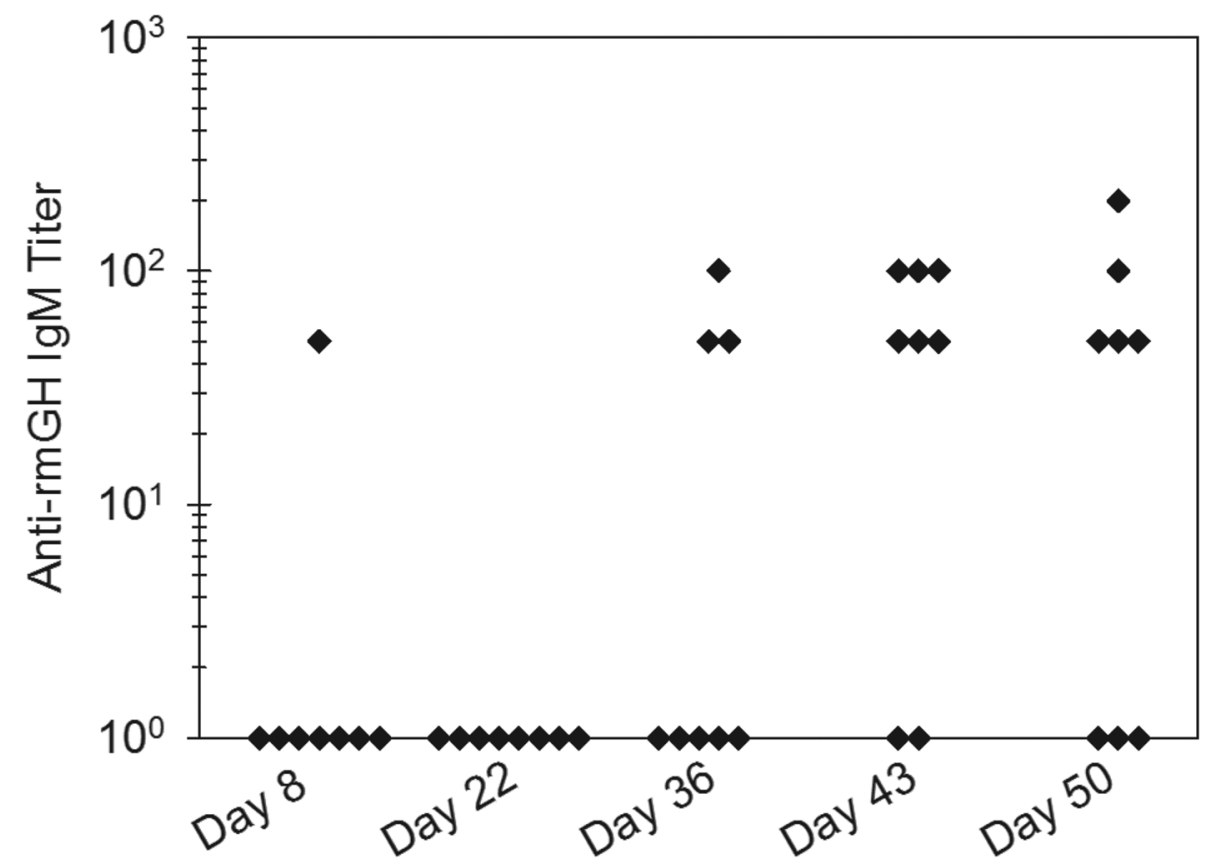


Table 1. The Number of Mice Out of the Total Number of Mice in Each Group Showing Anti-rmGH Antibodies at Day 22 in Study 2

\begin{tabular}{lccccc}
\hline Mouse Group & IgG1 & IgG2a & IgG2b & IgG3 & IgM \\
\hline rmGH & $0 / 8$ & $0 / 8$ & $2 / 8$ & $0 / 8$ & $2 / 8$ \\
$\begin{array}{l}\text { rmGH }+ \\
\text { silicone oil }\end{array}$ & $4 / 8$ & $0 / 8$ & $1 / 8$ & $0 / 8$ & $0 / 8$ \\
\hline \hline
\end{tabular}


Table 2. The Number of Mice Out of the Total Number of Mice in Each Group Showing Anti-rmGH IgM Antibodies at Days 8 through 50 in Study 2

\begin{tabular}{lccccc}
\hline Mouse Group & $\begin{array}{c}\text { Day } \\
8\end{array}$ & $\begin{array}{c}\text { Day } \\
22\end{array}$ & $\begin{array}{c}\text { Day } \\
36\end{array}$ & $\begin{array}{c}\text { Day } \\
43\end{array}$ & $\begin{array}{c}\text { Day } \\
50\end{array}$ \\
\hline rmGH & $2 / 8$ & $2 / 8$ & $0 / 8$ & $0 / 8$ & $0 / 8$ \\
$\begin{array}{l}\text { rmGH }+ \\
\text { silicone oil }\end{array}$ & $1 / 8$ & $0 / 8$ & $3 / 8$ & $6 / 8$ & $5 / 8$ \\
\hline \hline
\end{tabular}

